Article

\title{
Design of Human-Centered Collaborative Assembly Workstations for the Improvement of Operators' Physical Ergonomics and Production Efficiency: A Case Study
}

\author{
Luca Gualtieri, Ilaria Palomba $₫$, Fabio Antonio Merati, Erwin Rauch $₫$ and Renato Vidoni *(1) \\ Industrial Engineering and Automation (IEA), Faculty of Science and Technology, Free University of \\ Bozen-Bolzano, Piazza Università 5, 39100 Bolzano, Italy; luca.gualtieri@unibz.it (L.G.); \\ ilaria.palomba@unibz.it (I.P.); fabioantonio.merati@natec.unibz.it (F.A.M.); erwin.rauch@unibz.it (E.R.) \\ * Correspondence: renato.vidoni@unibz.it; Tel.: +39-0471-017111
}

Received: 11 March 2020; Accepted: 27 April 2020; Published: 29 April 2020

\begin{abstract}
Industrial collaborative robotics is one of the main enabling technologies of Industry 4.0. Collaborative robots are innovative cyber-physical systems, which allow safe and efficient physical interactions with operators by combining typical machine strengths with inimitable human skills. One of the main uses of collaborative robots will be the support of humans in the most physically stressful activities through a reduction of work-related biomechanical overload, especially in manual assembly activities. The improvement of operators' occupational work conditions and the development of human-centered and ergonomic production systems is one of the key points of the ongoing fourth industrial revolution. The factory of the future should focus on the implementation of adaptable, reconfigurable, and sustainable production systems, which consider the human as their core and valuable part. Strengthening actual assembly workstations by integrating smart automation solutions for the enhancement of operators' occupational health and safety will be one of the main goals of the near future. In this paper, the transformation of a manual workstation for wire harness assembly into a collaborative and human-centered one is presented. The purpose of the work is to present a case study research for the design of a collaborative workstation to improve the operators' physical ergonomics while keeping or increasing the level of productivity. Results demonstrate that the achieved solution provides valuable benefits for the operators' working conditions as well as for the production performance of the companies. In particular, the biomechanical overload of the worker has been reduced by $12.0 \%$ for the right part and by $28 \%$ for the left part in terms of manual handling, and by $50 \%$ for the left part and by $57 \%$ for the right part in terms of working postures. In addition, a reduction of the cycle time of $12.3 \%$ has been achieved.
\end{abstract}

Keywords: industry 4.0; collaborative robotics; physical ergonomics; human-robot collaboration; human-centered design; assembly; SME; small and medium sized enterprise

\section{Introduction}

Nowadays, production systems are shifting from mass production to mass customization [1]. As a consequence, in order to remain competitive and profitable, modern companies need further production flexibility, efficiency, and sustainability in terms of lot sizes, variants, and time-to-market. These conditions require the integration of adaptable, reconfigurable, and agile manufacturing systems and technologies characterized by a scalable degree of automation. The term "Industry 4.0 ", also known as the fourth industrial revolution, was initially introduced by a German government strategic 
initiative in 2011 [2] and represents the current transformation, which is affecting a large part of worldwide industrial companies.

Process sustainability is one of the drivers of the fourth industrial revolution, and it is defined as a multi-dimensional concept encompassing environmental, social, and economic aspects [3]. Operators' occupational health and safety (OHS) as well as wellbeing and satisfaction are crucial parts of social sustainability in industry. Manufacturing companies should consider the human element as their core and a valuable part by improving work conditions and developing human-centered production systems. In this context, a major role is played by work-related ergonomics. Even if ergonomics includes three different categories dealing with the physical, cognitive, and organizational aspects of the interaction between humans and systems, this paper mainly focuses on the aspects related to physical one. The International Ergonomics Association (IEA) defines physical ergonomics as the scientific discipline concerned with human anatomical, anthropometric, physiological, and biomechanical characteristics as they relate to physical activity [4].

A possible and concrete solution to improve the social sustainability in terms of physical ergonomics without neglecting the production efficiency is represented by the collaborative robotics [5,6], as demonstrated by the increasing scientific literature on such a topic. Castro et al. [7] developed an integrated robot simulation and digital human modeling aimed to be a tool to create and confirm successful ergonomic collaborative workstations. Lietaert et al. [8] proposed a model-based methodology to aid the layout design of a collaborative workcell by considering feasibility, reachability, safety, and ergonomics as constraints. Mateus et al. [9] provided an information-based generic methodology for collaborative assembly solution development, starting from CAD models. Petruck et al. [10] designed an ergonomic human-robot collaboration (HRC) workstation where intelligent sensors are used to adapt the system behavior to the way the working person works. Dombrowski et al. [11] presented an interactive and real-time physics simulation as a tool for workcell validation and optimization. Makrini et al. [12] developed a modular architecture used to enhance human-robot interaction (HRI) in assembly tasks. Schmidtler et al. [13] presented a study about the optimization of working conditions by adapting collaborative assistance systems in terms of human acceptance and well-being. Basically, all these works aimed to finalize design tools and methodologies for the realization of a new collaborative workstation. Conversely, just few works have addressed the problem of the conversion of an existing manual workstation into a collaborative one. In particular, Heydaryan et al. [14] developed an HRC workstation for the assembly of an automotive brake disc by implementing a hierarchical task analysis to allocate operational tasks to humans and robots based on productivity, quality, human fatigue, and safety considerations.

This paper presents the conversion of an industrial manual workstation for wire harness assembly into a collaborative one and its realization and validation. The conversion aims at improving the operators' physical ergonomics, in terms of reduction of biomechanical overload, and the company's productivity, in terms of cycle time. Before starting with the workstation conversion, the preliminary steps are introduced by proposing two algorithms. One is addressed to the evaluation of the physical ergonomics conditions, while the other is aimed at assessing the feasibility of using collaborative robotics. The first one is a framework based on three key questions that guide the evaluator towards the most suitable ergonomics assessment methods to be used. The second is a simplified version of the methodology proposed by Gualtieri et al. [15]. It allows for an easy and quick identification of the potentials for the adoption of collaborative solutions in terms of ergonomics and safety, product and process quality, and economics.

The paper is organized as follows. Section 2 describes the methodology adopted for transforming a manual assembly workstation into a collaborative one. Section 3 describes the industrial case study employed. Section 4 collects all the results. Finally, Section 5 discusses the technical measures designed for the workstation re-design according to ergonomics and production efficiency requirements and draws the possible future improvements. 


\section{Materials and Methods}

In order to design a new collaborative assembly workstation starting from an existing one by considering the physical ergonomics and production efficiency as main conversion goals, the following sequential steps, described in detail in the next subsections, were applied:

a) Analysis of the current situation in terms of physical ergonomics;

b) Evaluation of the potentials for collaborative robotics;

c) Workstation re-design for physical ergonomics and production efficiency enhancement.

\subsection{Analysis of the Current Situation in Terms of Physical Ergonomics}

A crucial part of the ergonomic re-design of an assembly workstation is the physical ergonomics assessment. A detailed analysis is needed to identify the tasks that present unsuitable conditions from the biomechanical point of view. To this end, a framework to assess the manual assembly activities that are typically carried out in a workstation is presented.

The idea was to evaluate the current conditions related to the assembly by considering the potentials of collaborative robots in terms of physical assistance. The proposed framework was inspired by the approach presented in the technical report ISO TR 12295 [16]. It was formulated for the evaluation of typical manual assembly tasks, which could be possibly supported by a fixed-position anthropomorphic collaborative robot. For this reason, other ergonomic evaluations related to two-handed whole-body pushing and pulling of loads were ignored [17]. The suggested framework, shown in Figure 1, mainly focuses on the evaluation of the biomechanical overload of neck, trunk, and/or upper limbs related to manual assembly tasks and is based on a key question analysis [16]. In particular, three key questions were adopted, focusing on: the manual handling of heavy objects, the repetitive tasks of upper limbs, and the awkward working postures. According to the proposed framework, for each positive key question a further physical ergonomics analysis must be performed to understand whether or not there are the needs for an ergonomics re-design by eventually integrating a collaborative robot. On the other hand, if all the key questions are negative, no problems are highlighted, and changes will be not required. The presented key questions were based on the following methodologies, respectively:

-the National Institute for Occupational Safety and Health (NIOSH) lifting equation for manual lifting of objects [18-20];

-the Occupational Repetitive Action (OCRA) for repetitive tasks (in check-list form) [21,22];

- the Rapid Upper Limb Assessment (RULA) for working postures [23].

The first two methods are discussed and partially developed into the technical report ISO TR 12295 and related ISO standards; the third method is an evaluation procedure mainly focused on working postures which differs from the one proposed into the technical report. It is worth noticing that the suggested framework does not aim to calculate occupational risks, but to evaluate which tasks of the manual assembly cycle are not suitable from the point of view of the biomechanical overload. This will be useful to identify which tasks could potentially be improved by integrating a collaborative robot to be used as a physical assistance system for the enhancement of operators' work conditions. 


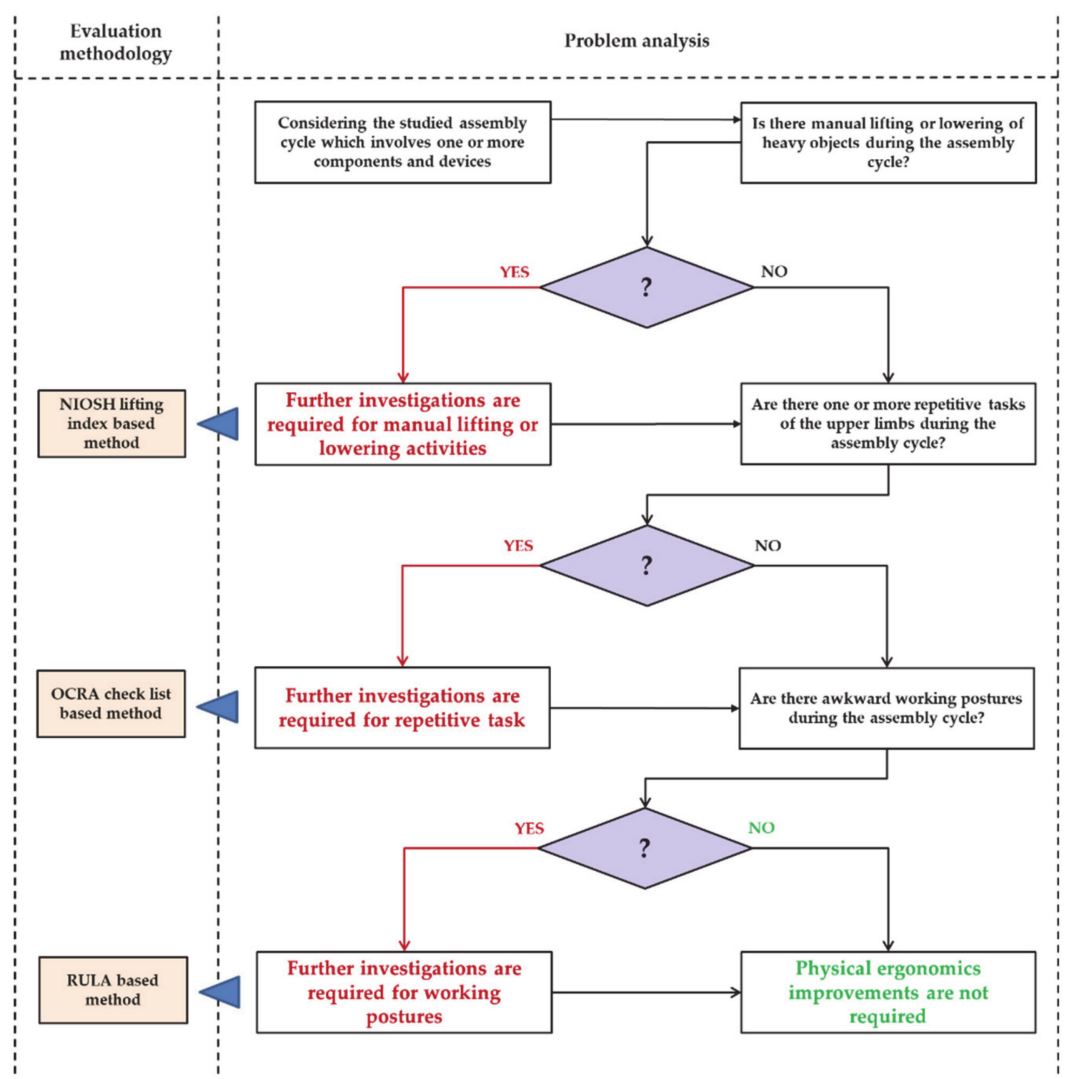

Figure 1. Framework for the identification of not-ergonomic tasks which could be improved by integrating a collaborative robot to be used as a physical assistance system.

\subsection{Evaluation of the Potential for Collaborative Robotics}

A so-called Quick Assessment algorithm is proposed to identify if the current assembly cycle has the potential to be performed (or not) in collaboration with a robot. The sense of such a Quick Assessment algorithm is to propose a simple and easy to use assessment methodology that can also be applied by small and medium-sized enterprises (SMEs). This approach is a simplified version of the study presented in [15]. Basically, the simplification is addressed to better support the technicians without specific skills and experiences by providing a preliminary tool for a quick and simple evaluation. Firstly, it helps SMEs in understanding their weaknesses with respect to a certain assembly process. This will be useful to define priorities and understand where to focus improvement interventions. Secondly, this will support them in quantifying the potential benefits of using collaborative robots to fill these gaps. This should overcome the technological barriers related to the lack of technical and organizational knowledge about a proper implementation of collaborative robots. The evaluation is based on the analysis of five process critical issues (PCIs) ranging from safety and ergonomics, product and/or process quality to economics (see the first and second columns of Table 1). In accordance with the Industry 4.0 principles, which aim to promote sustainable production systems, the algorithm is organized to provide more relevance to the operators' occupational safety and wellbeing. After that, the procedure considers the relevance of process and product quality, which is a crucial matter for SMEs. Finally, the last consideration refers to economic factors. The algorithm requires the scoring of the five PCIs for each task of the assembly cycle. The score is an integer from 0 to 3 , where 0 means that there are no possible improvements for the analyzed task and 3 that they are extremely recommendable. 
Table 1. Quick Assessment of the actual manual assembly of wire harness.

\begin{tabular}{|c|c|c|c|}
\hline Category & Process Critical Issue (PCI) & $\begin{array}{c}\text { Weight } \\
\left(W_{i}\right)\end{array}$ & $\begin{array}{c}\text { Score } \\
\left(S_{i j}\right)\end{array}$ \\
\hline \multirow[t]{3}{*}{$\begin{array}{l}\text { Safety and } \\
\text { ergonomics }\end{array}$} & $\begin{array}{c}\text { PCI 1: } \\
\text { Are there physical ergonomic problems related to: } \\
\text { - lifting/lowering or carrying of objects } \\
\text { OR } \\
\text {-repetitive tasks of the upper limbs characterized by repeated work cycles } \\
\text { OR } \\
\text { —static or awkward working postures? }\end{array}$ & 3 & $0-3$ \\
\hline & $\begin{array}{l}\text { PCI 2: } \\
\begin{array}{c}\text { Are there occupational risks for the operator's safety which are not properly } \\
\text { managed } \\
\text { OR }\end{array} \\
\begin{array}{c}\text { occupational risk for operator's health which are not properly managed? (not yet } \\
\text { considered in the previous point) }\end{array}\end{array}$ & 3 & $0-3$ \\
\hline & $\begin{array}{c}\text { PCI 3: } \\
\text { Is there high work monotonousness } \\
\text { OR } \\
\text { very low requirements in terms of task qualification of the manual work? }\end{array}$ & 3 & $0-3$ \\
\hline $\begin{array}{c}\text { Product } \\
\text { and Process } \\
\text { Quality }\end{array}$ & $\begin{array}{c}\text { PCI 4: } \\
\text { Are there not-constant/satisfactory product quality } \\
\text { OR } \\
\text { unsuitable process quality levels according to the nominal values } \\
\text { (i.e., characterized by high variability/low standardization)? }\end{array}$ & 2 & $0-3$ \\
\hline Economics & $\begin{array}{l}\text { PCI 5: } \\
\text { Is there an inefficient use of time and/or resources without a real advancement of } \\
\text { production, which means tasks which cannot generate value to the final } \\
\text { costumers (not value-added activities) } \\
\text { OR }\end{array}$ & 1 & $0-3$ \\
\hline & $\begin{array}{l}\text { (*) Score meaning: } \\
\text { 0-Improvements are not required for that activity / the problem does not exists } \\
\text { 1-The achievable improvements could be moderate for that activity } \\
\text { 2-The achievable improvements could be good for that activity } \\
\text { 3-Improvements could be very significant for that activity }\end{array}$ & & \\
\hline
\end{tabular}

The potential value $\left(\mathrm{Pval}_{j}\right)$ in terms of HRI for the $j$-th task is calculated as a weighted sum of the scores $\left(S_{i j}\right)$ given to the five PCIs:

$$
\operatorname{Pval}_{j}=\sum_{i=1}^{5} S_{i j} * W_{i} ; \quad j=1, \ldots, n_{t} .
$$

In Equation (1), $n_{t}$ is the number of tasks of the assembly process. The PCI weights $W i$ (stated in the third column of Table 1) are introduced in order to follow the abovementioned considerations. The index Pval ${ }_{j}$, computed according to Equation (1) ranges from 0 to 36 . The resulting value describes the potential for a successful adoption of collaborative solutions in the analyzed manual tasks by using the following five classes:

-No potential: Pvalj $=0$;

-Low potential: $1 \geq$ Pvalj $>9$;

-Modest potential: $9 \geq$ Pvalj $>18$;

-Good potential: $18 \geq$ Pvalj $>27$;

-High potential: $27 \geq$ Pvalj $\geq 36$.

\subsection{Workstation Re-Design for Physical Ergonomics and Production Efficiency Enhancement}

If the physical ergonomics assessment highlights unsuitable work conditions, the process and the workstation shall be improved. According to the (positive) Quick Assessment results, this can be done by exploiting the benefits of the integration of a collaborative robot in lowering the biomechanical overload for the operator. In addition to the introduction of the collaborative robot, another important aspect 
concerns the development of an ergonomically optimized layout of the workspaces. The proposed re-design follows the guidelines presented in the EN ISO 14738 [24]. Basically, this standard establishes the principles for dimension derivation from anthropometric measurements and their application to the design of workstations.

On the other hand, improvement of the collaborative workstation in terms of productivity (and hence of cycle time) is made by properly setting the layout of the new workstation. In particular, the new layout is chosen on the basis of the following production variables:

-Number of robots $(\mathrm{R})$;

-Number of kinds of workpieces $(\mathrm{P})$;

-Number of workers (W);

-Number of working areas (A).

By combining these four production variables, it is possible to identify 16 different layouts for the collaborative workstation, as shown in Table 2. The more convenient layout will depend on the specific values assumed by such variables for the analyzed assembly process.

Table 2. Classification of the possible layouts for collaborative workstations according to the following variables: Number $(\mathrm{Nr})$ of robots $(\mathrm{R}), \mathrm{Nr}$ of different kind of workpieces $(\mathrm{P})$ and related assembly tasks which are intended to be allocated to the robot, $\mathrm{Nr}$ of workers (W), and $\mathrm{Nr}$ of working areas (A).

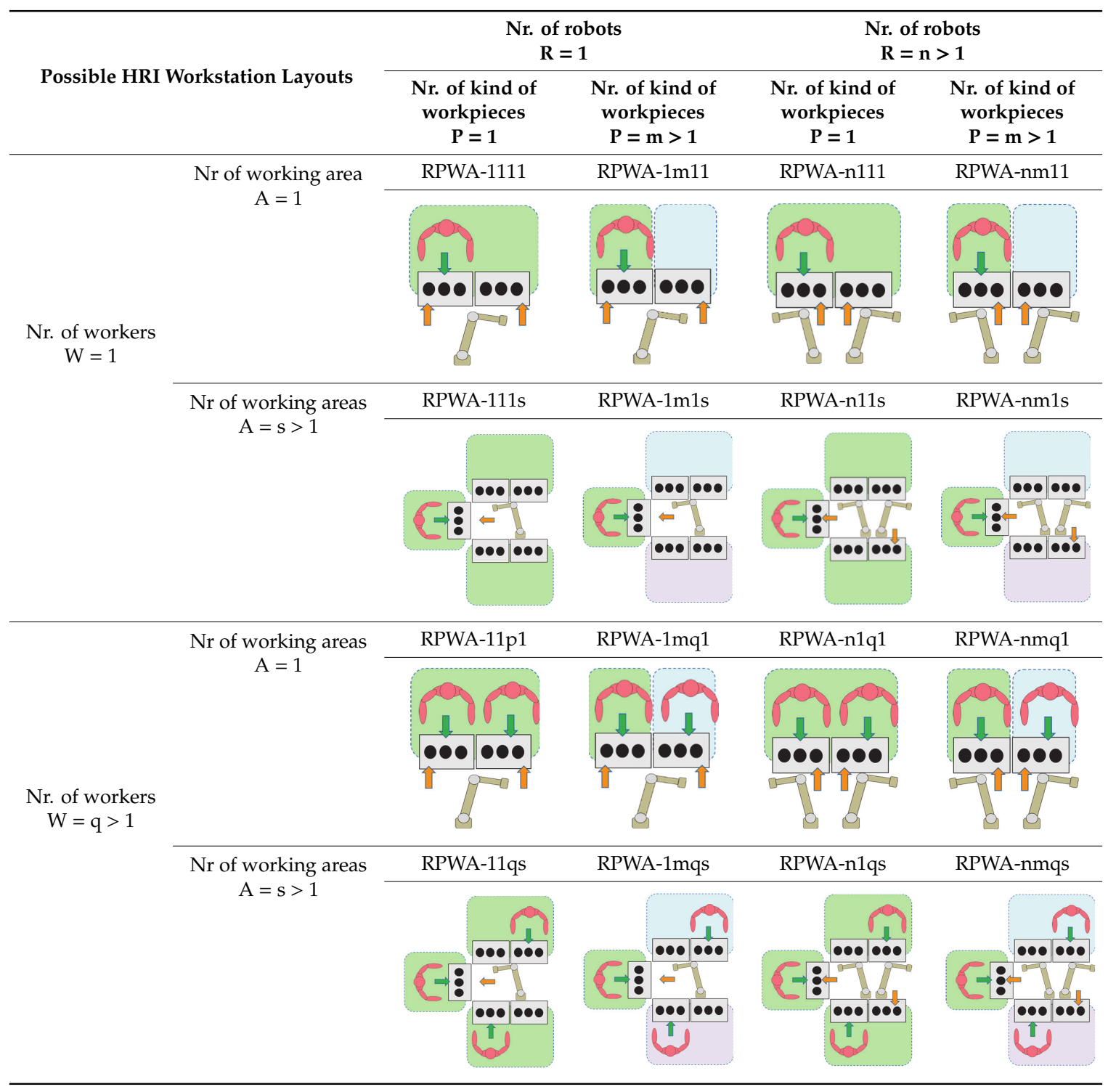




\section{Test Case Study Description}

The investigated case study was proposed by the company ELVEZ d.o.o. [25], a manufacturer of cable harnesses and processer of plastic components located in Višnja Gora, Slovenia. The company asked for a robotic collaborative system able to fulfill the assembly of wire harnesses for the automotive sector while interacting with an operator in a safe, ergonomic, and efficient way. Such a case study is one of the manufacturing challenges proposed in the first call of ESMERA (European SMEs Robotics Applications), the European Union's "Horizon 2020" project for research and innovation [26]. The solution to the challenge outlined in this paper is part of the project Wire Cobots, which is funded by ESMERA and developed by the research group of the Smart Mini Factory Lab (SMF) of the Free University of Bolzano-Bozen [27] and Carretta s.r.1. [28], a company specializing in the design and installation of industrial automation solutions, located in Quinto di Treviso, Italy.

The wire harnesses are currently assembled on a manual assembly line made by two stations working on average six days per week with three shifts $(8 \mathrm{~h} / \mathrm{shift})$ per day. The average total year production of the line is 900,000 pieces, computed as follows:

$500 \mathrm{pcs} /$ shift $\times 3$ shifts $\times 6$ days $/$ week $\times 50$ weeks $\times 2$ lines $=900,000$ pcs $/$ year.

It can vary between 750,000 and 1,050,000 pcs/year depending on the number of workdays per week as a result of market interest. An efficiency of $40 \mathrm{~s} / \mathrm{unit}$ is considered for each station.

The assembly process consists of taping together three groups of wires with connectors by means of a taping pistol. The wires are sequentially inserted by the worker into dedicated assembly jigs (see Figure 2 [29] and Figure 3) and then fastened together by means of the isolating tape in seven different spots (Figure 2b). The assembly process consists of 19 elementary tasks, listed in Table 3 together with the average time. Since the case study refers to an industrial challenge provided by a company, the publication of some sensitive data (e.g., the standard deviation of the task time) is not possible. The total assembly cycle lasts on average $40 \mathrm{~s}$. All the tasks can be conceptually grouped into two groups: the group of operations related to wire insertion (tasks 1-5, 9,10,19 in Table 3-see Figure 2a) and the one related to the tapings (tasks 6-8, 11-18 in Table 3-see Figure 2b). The total cycle time is roughly divided in half between these two groups of tasks.

The company Elvez d.o.o. wants to make this manual assembly workstation collaborative in order to improve the following main metrics:

-Physical ergonomics: the new process should provide better physical work conditions to the operators;

-Productivity: the new cycle time should be the same as-or shorter than-the current manual process.
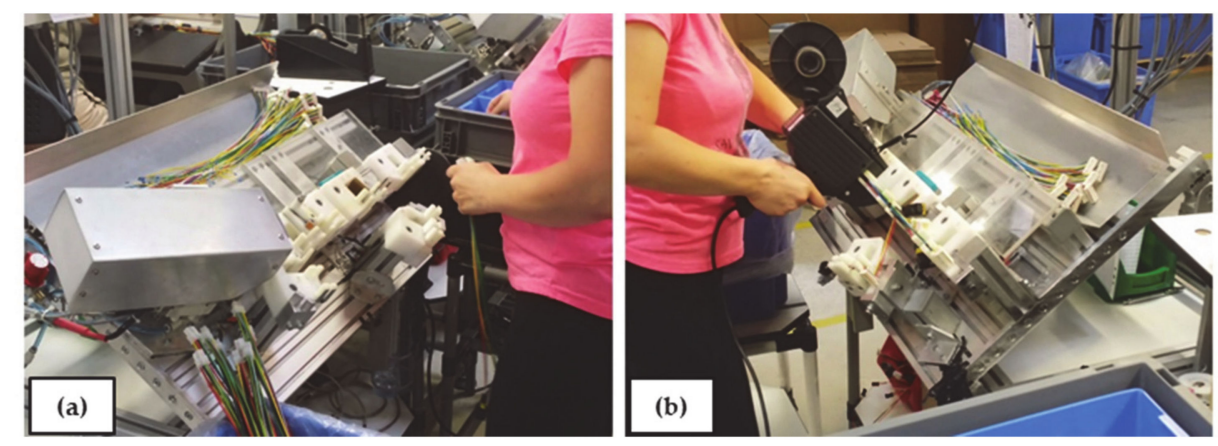

Figure 2. Wire harness manual assembly workstation at the ELVEZ d.o.o. company [29]: tasks related to wire insertion (a) and tasks related to the tapings (b). 


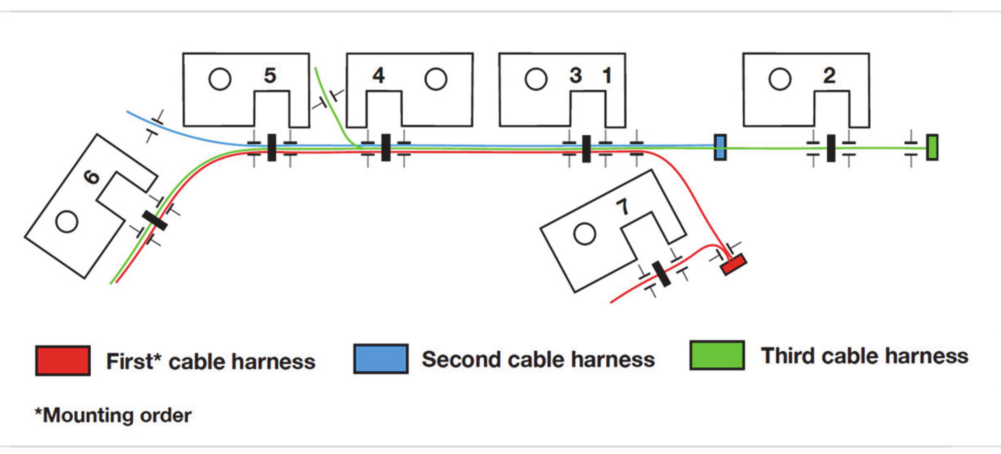

Figure 3. Layout of the assembly jigs and related position of wires and tape spots.

Table 3. Cable harness manual assembly sequence and related average task time.

\begin{tabular}{|c|c|c|}
\hline Nr. & Task & Average Task Time (s) \\
\hline 1 & Taking $1^{\text {st }}$ wire harness & 2 \\
\hline 2 & Positioning $1^{\text {st }}$ wire harness & 1 \\
\hline 3 & Taking $2^{\text {nd }}$ wire harness & 3 \\
\hline 4 & Positioning $2^{\text {nd }}$ wire harness & 3 \\
\hline 5 & Adjusting $1^{\text {st }}$ and $2^{\text {nd }}$ wire harness & 2 \\
\hline 6 & Taking taping pistol & 2 \\
\hline 7 & Performing $1^{\text {st }}$ taping & 1 \\
\hline 8 & Depositing taping pistol & 1 \\
\hline 9 & Taking $3^{\text {rd }}$ wire harness & 3 \\
\hline 10 & Positioning $3^{\text {rd }}$ wire harness & 5 \\
\hline 11 & Taking taping pistol & 2 \\
\hline 12 & Performing $2^{\text {nd }}$ taping & \multirow{6}{*}{10} \\
\hline 13 & Performing $3^{\text {rd }}$ taping & \\
\hline 14 & Performing $4^{\text {th }}$ taping & \\
\hline 15 & Performing $5^{\text {th }}$ taping & \\
\hline 16 & Performing $6^{\text {th }}$ taping & \\
\hline 17 & Performing $7^{\text {th }}$ taping & \\
\hline 18 & Depositing taping pistol & 1 \\
\hline 19 & Storing the wire harnesses & 4 \\
\hline & Total assembly time (s) & 40 \\
\hline
\end{tabular}

\section{Results}

\subsection{Analysis of the Current Situation in Terms of Physical Ergonomics}

A physical ergonomics assessment of the manual assembly workstation was carried out by means of the framework proposed and discussed in Section 2.1. The application of the proposed approach to our case study is shown in Table 4. The results show that the key questions related to repetitive upper limbs tasks and awkward working postures were positive. Therefore, further ergonomics evaluations on these aspects are needed. An OCRA check list and a RULA analysis were performed and discussed in Section 4.1.1 and Section 4.1.2., respectively. Conversely, since the assembly tasks did not present manual lifting or lowering of objects of $3 \mathrm{~kg}$ or more, the NIOSH-based evaluation was not necessary. 
Table 4. Preliminary identification of unsuitable work conditions related to physical ergonomics for the case study of manual assembly cycle (inspired by ISO TR 12295 [16]).

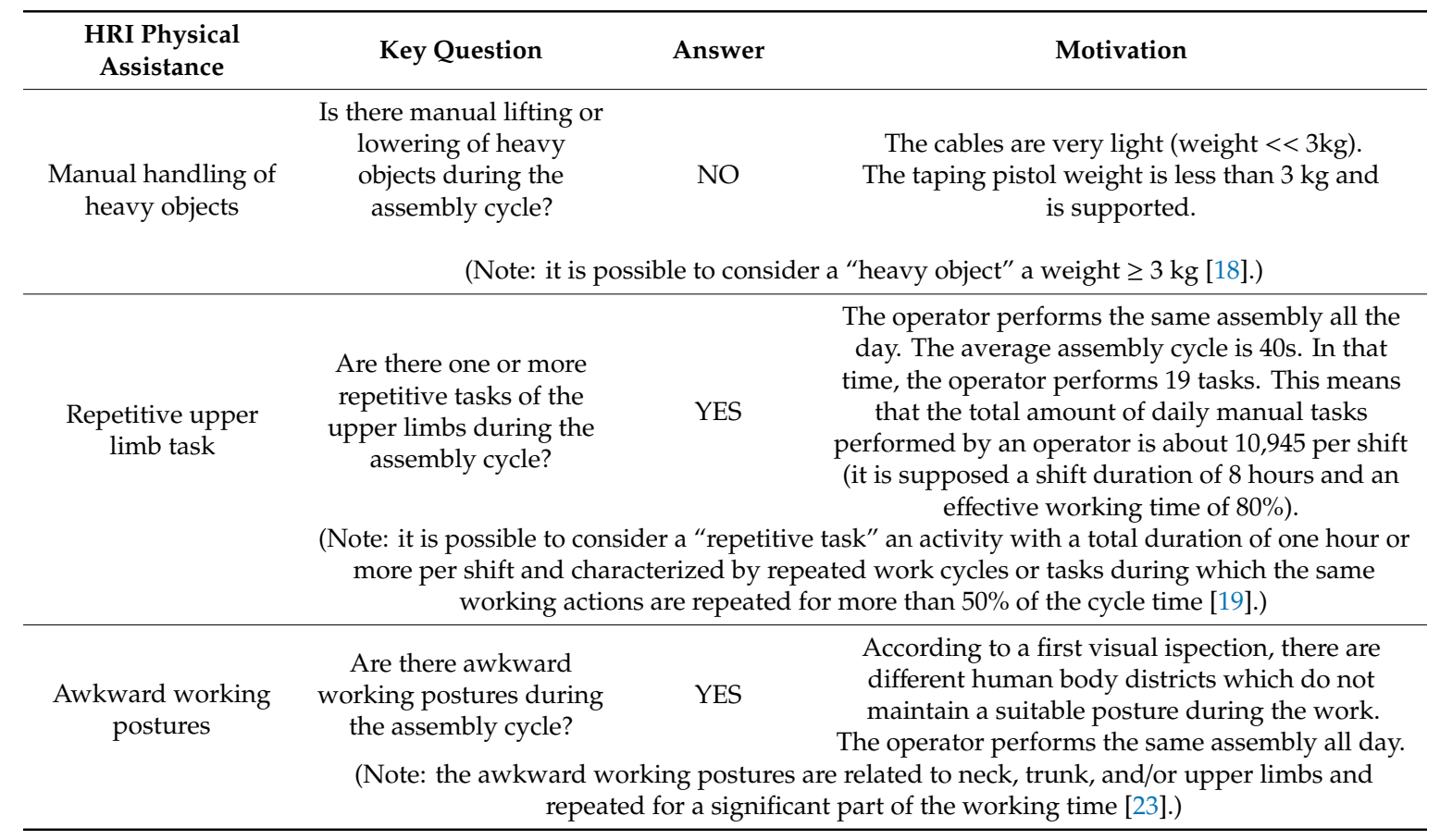

\subsubsection{The OCRA Analysis Results}

The analysis of the effects provided by manual handling of low loads at high frequency was based on the OCRA check list [21,22]. For the reader's convenience the OCRA method is recalled in "Annex A". Table 5 summarizes all the variables requested by the OCRA check list for the evaluation of the biomechanical overload and the related motivations for those choices. The table also shows the final estimation of the workstation risk value: "medium" for both the right and the left part. Major technical problems come from the static frequency of actions (which causes a multiplier equal to 4.5 for both the sides) and from awkward postures, especially for the hands (multiplier equal to 8 for both the sides). Since it was behind the aim of this work to provide organizational improvements, the ergonomics re-design of the workstation was focused on the technical aspects of the abovementioned multipliers. Therefore, only the frequency of technical actions and the awkward postures were considered in the new workstation proposal (force, stereotype, and additional factors are not a problem in the current assembly process).

\subsubsection{The RULA Analysis Results}

The preliminary key questions underline the need for further investigations about the working postures. In order to identify which tasks of the entire assembly cycle are less suitable from the postural point of view, the RULA analysis was performed for each task summarized in Table 3. This subdivision is useful to identify the least suitable manual tasks that are the best candidates to be potentially performed by the collaborative robot. Further theoretical information about the methodology and the evaluation are provided in "Annex A". Muscle use and force/load scores were ignored in this case, since the analysis was related to postures. Nevertheless, the related values were calculated for all the tasks and they were all equal to zero. The procedure was repeated in detail for each working task. The final RULA values related to the assembly cycle (the so-called overall section " $\mathrm{C}$ ") are summarized in Table 6. A detailed analysis of each body district for all the assembly tasks is provided in Tables A1 and A2 of "Appendix A". 
Table 5. Summary of the multipliers and final estimation of the workstation risk (manual workstation).

\begin{tabular}{|c|c|c|c|c|}
\hline \multicolumn{2}{|c|}{ Multiplier } & $\begin{array}{c}\text { Right } \\
\text { Part Value }\end{array}$ & $\begin{array}{c}\text { Left } \\
\text { Part Value }\end{array}$ & Motivation \\
\hline \multicolumn{2}{|c|}{ Recovery multiplier } & \multicolumn{2}{|c|}{1.33} & $\begin{array}{l}\text { The shift }(8 \mathrm{~h}) \text { is interspersed with a break }(1 \mathrm{~h}) \text {. As a result, } \\
\text { the operator works for } 4 \text { hours without a recovery period. }\end{array}$ \\
\hline \multicolumn{2}{|c|}{$\begin{array}{l}\text { Constant of frequency } \\
\text { (dynamic actions) }\end{array}$} & 4 & 4 & $\begin{array}{l}\text { The movements of the arms are rapid ( 40 action/min), } \\
\text { interruptions are infrequent and uneven. }\end{array}$ \\
\hline \multicolumn{2}{|c|}{$\begin{array}{l}\text { Constant of frequency } \\
\text { (static actions) }\end{array}$} & 4.5 & 4.5 & $\begin{array}{l}\text { The operator is handling the taping pistol and the cables for } \\
\text { all the assembly cycle (there is a pinch for more than the } 80 \% \\
\text { of the time for both the right and the left hands). }\end{array}$ \\
\hline \multicolumn{2}{|c|}{ Force multiplier } & 0 & 0 & $\begin{array}{l}\text { According to the operator interviews, the assembly tasks do } \\
\text { not require the use of force (Borg scale values lower than } 3 \text { ). }\end{array}$ \\
\hline \multirow{4}{*}{$\begin{array}{c}\text { Posture and } \\
\text { movements } \\
\text { multiplier }\end{array}$} & Shoulder & 6 & 1 & \multirow{4}{*}{$\begin{array}{l}\text { The movements and related postures were studied according } \\
\text { to the guidelines provided in the check list. }\end{array}$} \\
\hline & Elbow & 2 & 6 & \\
\hline & Wrist & 0 & 0 & \\
\hline & Hand & 8 & 8 & \\
\hline \multicolumn{2}{|c|}{ Stereotype } & 0 & 0 & No stereotype. \\
\hline \multicolumn{2}{|c|}{ Additional factors score } & 0 & 0 & No additional factors. \\
\hline \multicolumn{2}{|c|}{ Multiplier for net duration } & \multicolumn{2}{|c|}{0.95} & $\begin{array}{l}\text { The total net duration of the repetitive tasks was estimated to } \\
361-420 \mathrm{~min} / \text { shift, which takes into account the unplanned } \\
\text { interruptions that may occur. }\end{array}$ \\
\hline \multicolumn{2}{|c|}{ Final Check-list values } & 15.8 & 15.8 & \multirow{2}{*}{ Medium red } \\
\hline \multicolumn{2}{|c|}{ Final risk estimation } & Medium & Medium & \\
\hline
\end{tabular}

Table 6. Final Rapid Upper Limb Assessment (RULA) values (overall section "C" table) for the analyzed assembly cycle.

\begin{tabular}{|c|c|c|c|}
\hline Nr. & Task & Left Value & Right value \\
\hline 1 & Taking $1^{\text {st }}$ wire harness & 5 & 4 \\
\hline 2 & Positioning $1^{\text {st }}$ wire harness & 3 & 3 \\
\hline 3 & Taking $2^{\text {nd }}$ wire harness & 5 & 6 \\
\hline 4 & Positioning $2^{\text {nd }}$ wire harness & 6 & 7 \\
\hline 5 & Adjusting $1^{\text {st }}$ and $2^{\text {nd }}$ wire harness & 6 & 7 \\
\hline 6 & Taking taping pistol & 5 & 5 \\
\hline 7 & Performing $1^{\text {st }}$ taping & 6 & 7 \\
\hline 8 & Depositing taping pistol & 6 & 5 \\
\hline 9 & Taking $3^{\text {rd }}$ wire harness & 4 & 4 \\
\hline 10 & Positioning $3^{\text {rd }}$ wire harness & 6 & 7 \\
\hline 11 & Taking taping pistol & 5 & 5 \\
\hline 12 & Performing $2^{\text {nd }}$ taping & 6 & 7 \\
\hline 13 & Performing $3^{\text {rd }}$ taping & 6 & 7 \\
\hline 14 & Performing $4^{\text {th }}$ taping & 6 & 7 \\
\hline 15 & Performing $5^{\text {th }}$ taping & 6 & 7 \\
\hline 16 & Performing $6^{\text {th }}$ taping & 6 & 7 \\
\hline 17 & Performing $7^{\text {th }}$ taping & 5 & 7 \\
\hline 18 & Depositing taping pistol & 3 & 3 \\
\hline 19 & Storing the wire harnesses & 6 & 7 \\
\hline \multicolumn{2}{|r|}{ Max values (Overall values) } & 6 & 7 \\
\hline
\end{tabular}


As for the OCRA check list approach, this representation of the results makes it possible to quickly and efficiently understand the needs for an ergonomic re-design of the layout and/or process. The workstation final values (left and right side) were equal to the maximum values calculated for all the analyzed tasks. In general, with the exception of tasks 2, 9, and 18, all the others required important improvements in terms of working postures. From the technical point of view, this could be achieved by re-designing the workspaces in a more ergonomic way and by adding a collaborative robot for performing the most stressful tasks.

\subsection{Evaluation of the Potential for Collaborative Robotics}

With reference to the studied assembly process, the proposed algorithm was not applied to each of the 19 identified tasks (Table 3), since many of them are the same operation repeated in different moments. In particular, this is the case of the taking and the positioning of cable harness (tasks 1-4, 9-10), and the picking and the dropping off the taping pistol, as well as the related taping tasks (6-8, 11-18). It is worth noticing that although the grouped tasks have a different duration and involve different components, for the purpose of assessing their potentials in HRI they behave like they are the same task. Additionally, the grouping of the harness picking/placing as well as of picking/placing the taping pistol and taping avoids introducing additional tasks (e.g., the transfer of the harness/pistol from human to robot or vice-versa), since each task group is performed by the same human/robot resource.

The scoring of the five PCIs for each of the four groups of the studied assembly cycle is shown in Table 7. Considering the results of the physical ergonomics analysis presented in Section 4.1, the first and third groups received the highest possible value for the first process critical issue (PCI 1). In addition, according to a preliminary risk analysis, none of the groups received a value for the aspects related to the occupational risks (PCI 2). On the other hand, due to the repetitiveness of the assembly cycle, all the groups received a value equal to two for the process critical issue related to work monotonousness (PCI 3). Since the taping tasks often require to be re-performed, the third group (only) received a value equal to two for the process critical issue related to the product and process quality (PCI 4). Finally, the first and the last groups received a value equal to three for the last process critical issue since they are classified as not value-added (PCI 5). The third group received a value equal to one due to the fact that only the picking and dropping off of the taping pistol are tasks of the group classified as not value-added.

Table 7. Quick Assessment of the actual manual assembly of wire harness.

\begin{tabular}{ccccc}
\hline & \multicolumn{5}{c}{ Score $\left(S_{i j}\right)$} \\
\cline { 2 - 5 } Process Critical Issue & Task & Task & Task & Task \\
& $\mathbf{1 - 4}, \mathbf{9 - 1 0}$ & $\mathbf{5}$ & $\mathbf{6 - 8 ,} \mathbf{1 1 - 1 8}$ & $\mathbf{1 9}$ \\
\hline PCI 1 & 3 & 2 & 3 & 2 \\
\hline PCI 2 & 0 & 0 & 0 & 0 \\
\hline PCI 3 & 2 & 2 & 2 & 2 \\
\hline PCI 4 & 0 & 0 & 2 & 0 \\
\hline PCI 5 & 3 & 0 & 1 & 3 \\
\hline Potential value (Pval $)$ & $\mathbf{1 8}$ & $\mathbf{1 2}$ & $\mathbf{2 0}$ & $\mathbf{1 5}$ \\
\hline Potential class & good & good & good & good \\
\hline
\end{tabular}

According to the resulting Pval indexes (see Table 7), there are good potentials for the implementation of HRI solutions for all the identified groups of tasks. In particular, the highest values were related to the first group ( Pval $_{G 1}$ equal to 18) and to the third group ( vval $_{G 3}$ equal to 20). If in addition to the evaluated PCIs the technical feasibility for the robot execution was considered, the tasks of the third group were by far the ones with more potential, since the picking and handling (group 1) of flexible 
and tangle components, such as wires, are very complex and expensive tasks (both in terms of time as well as investments) for a robotic system.

\subsection{Workstation Re-Design for Physical Ergonomics and Production Efficiency Enhancement}

The results in Section 4.1 show that the physical ergonomics of the manual workstation need to be improved, while the ones in Section 4.2 demonstrate that there is a good potential for collaborative robotics. The highest score in terms of potential for collaborative robots was the one of the taping tasks, which are the ones that mostly contribute to the biomechanical overload for the operator. In addition, in order to provide flexible and cost-effective solutions, there is the necessity to improve the productivity of the current assembly cycle without using fully automated solutions. This means that a sharing of tasks and workspaces between human and automated solutions could be a suitable solution. These conditions make the use of the collaborative robot as a physical assistance system very attractive, especially if properly combined with an ergonomic re-design of the workspace. Based on such results, the manual assembly workstation was re-designed by introducing a collaborative robot supporting the worker in the tapings. In order to further improve the physical ergonomics of the new workstation and its productivity, both the workstation and the assembly cycle were re-organized.

A layout RPWA-1112 (one robot, one type of workpiece, one operator, two working areas), among the ones suggested in Section 2.3, was chosen. The main considerations that led to the adoption of this layout with two working areas were:

- the need to assemble only one kind of product;

- the need to improve productivity without increasing company costs;

-the small dimension of the assembly panel (about $500 \times 300 \mathrm{~mm}$ ), that might lead the operator and the robot to hinder each other preventing a safe sharing of the working area;

- the sequentiality of most of the tasks to be performed, that does not make it possible to parallelize operations between human and robot.

The adoption of two working areas, i.e., a double-panel workstation, overcomes the issues stressed above. Indeed, while the operator is working on one panel, the robot works on the other, and vice-versa (basically they work in parallel).

The results of the physical ergonomics assessment (see Section 4.1.) highlight that the current assembly process leads the worker to assume awkward postures as well as to perform unsuitable repetitive movements. A summary of the highlighted problems as well as the related solutions to improve the manual handling and the postural conditions is given in Table 8.

Table 8. Potential ergonomic improvements according to the physical ergonomics assessment.

\begin{tabular}{ccc}
\hline $\begin{array}{c}\text { Involved Body Part, Posture, } \\
\text { and Movements }\end{array}$ & Involved Task & Possible Solutions \\
\hline $\begin{array}{c}\text { upper arm position and } \\
\text { movements }\end{array}$ & tapings & Use of a collaborative robot as support for tapings \\
\hline $\begin{array}{c}\text { wrist position and twist and } \\
\text { movements }\end{array}$ & all tasks & $\begin{array}{c}\text { Re-design of the worktable areas according to main } \\
\text { anthropometric requirements [24] }\end{array}$ \\
\hline neck position & all tasks & $\begin{array}{c}\text { Re-design of the worktable areas according to main } \\
\text { anthropometric requirements [24] }\end{array}$ \\
\hline trunk position & all tasks & Possible solutions \\
\hline Involved work-related feature & all tasks & $\begin{array}{c}\text { Use of a collaborative robot as support for the } \\
\text { reduction of manual frequency }\end{array}$ \\
\hline activity rhythm & all tasks & $\begin{array}{c}\text { Use of a collaborative robot as support for the balance } \\
\text { of the overload between left and right body sides }\end{array}$ \\
\hline
\end{tabular}

With reference to the working area, it was designed according to the guidelines defined in the EN ISO 14738 [24]. Since for productivity purposes the new workstation will have two working areas, i.e., 
two side by side assembly panes, the optimal working area was designed by properly matching two single optimal zones. The resulting working area is shown in Figure 4. The same figure also shows the new layout of the working area. According to such a layout, the assembly panel is completely included in the optimal area as well as the picking zone of the boxes for cables supply. Therefore, during the assembly process, the operator moves in a zone that optimizes the working postures.

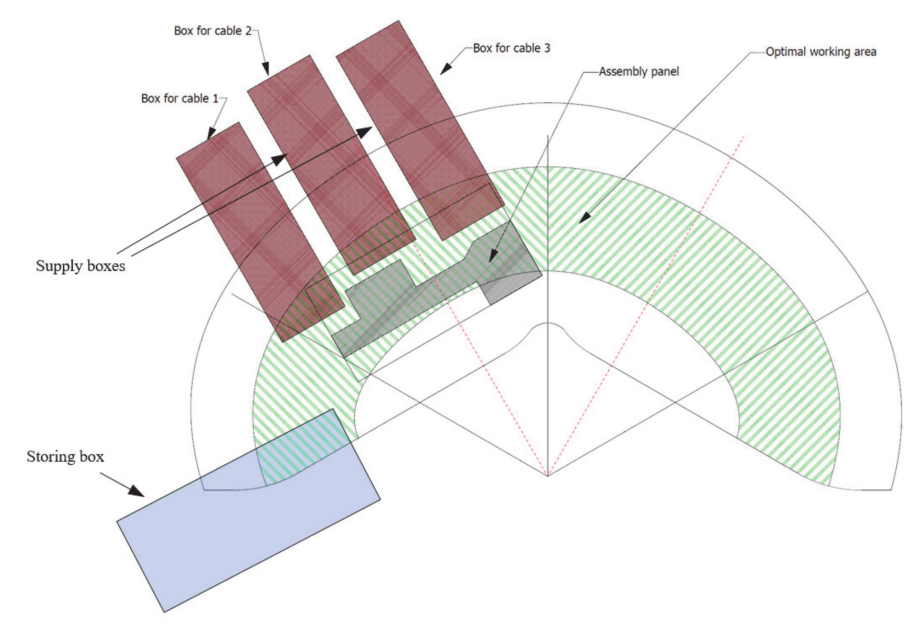

Figure 4. New assembly workstation working area and related layout.

As far as the workstation is concerned, its re-design was based on the EN ISO 14738 guidelines too. In particular, the following features have been provided:

- the working area is inclined $30^{\circ}$ with respect to the horizontal, that is, the orientation that minimize the operator's wrist twist;

-the angle with respect to the vertical axis between the two assembling panels is $120^{\circ}$. Such an arrangement of the assembling panels allows the operator to work on both the panels with a minimal trunk twist and without colliding with the adjacent panel;

-the workstation height as well as the panel positions are adjustable, so that they can fit the anthropometric measure of the operator working on it.

A preliminary numerical validation of the physical ergonomics of the re-designed working area and workstation was carried out in "Siemens Tecnomatix Process Simulate" [30]. Such a simulation software makes it possible to perform postural analysis (RULA index) for manufacturing tasks. This preliminary evaluation showed that a great improvement in terms of operators' working postures can be obtained with the proposed workstation. Indeed, the maximum values of the RULA scores were decreased from 6 for the left arm and 7 for the right arm of the old workstation to 3 for both the arms.

The collaborative robot has been placed at the back side of the workstation, while the worker at the front one, i.e., they operate one in front of the other, with the assembling panels interposed. The robot is located on the floor level and moves towards the panel from the underside. In order to equally and easily reach the taping zones of both the panels, the robot has been placed in the middle of the two panels. Such a placement of the robot drastically reduces the possibility of collision with the operator's head. However, since the robot moves under the workstation, if the operator is in a seated position, collisions between the robot and the operator's legs could happen. In order to avoid such a risk, the operator will use a high stool that permits an upright position or will directly take a standing position. The suggested design for the conversion of the manual assembly workstation for the wire harness assembly has been implemented in the laboratory prototype shown in Figure 5. 

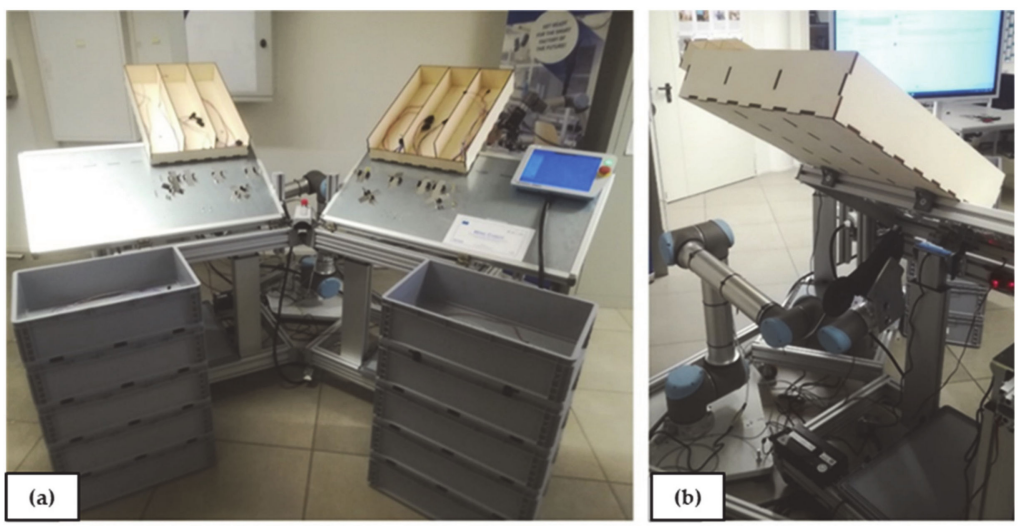

Figure 5. Laboratory prototype of the new collaborative workstation: front (a), back (b) view.

\subsection{Collaborative Workstation Assessment}

In order to experimentally assess the physical ergonomics and production efficiency improvements of the proposed solution, several wire-assembly tests were carried out on the developed prototype (see Figure 6). The laboratory tests involved two persons with no knowledge of robotics. The age, gender, anthropometric features, and work skills of the two candidates were very similar and reasonably represent the "real" workers of the company. The ergonomic assessments (OCRA index and RULA analysis) of the new workstation were carried out by the members of the SMF lab with expertise in biomechanical overload analysis and collaborative robotics.
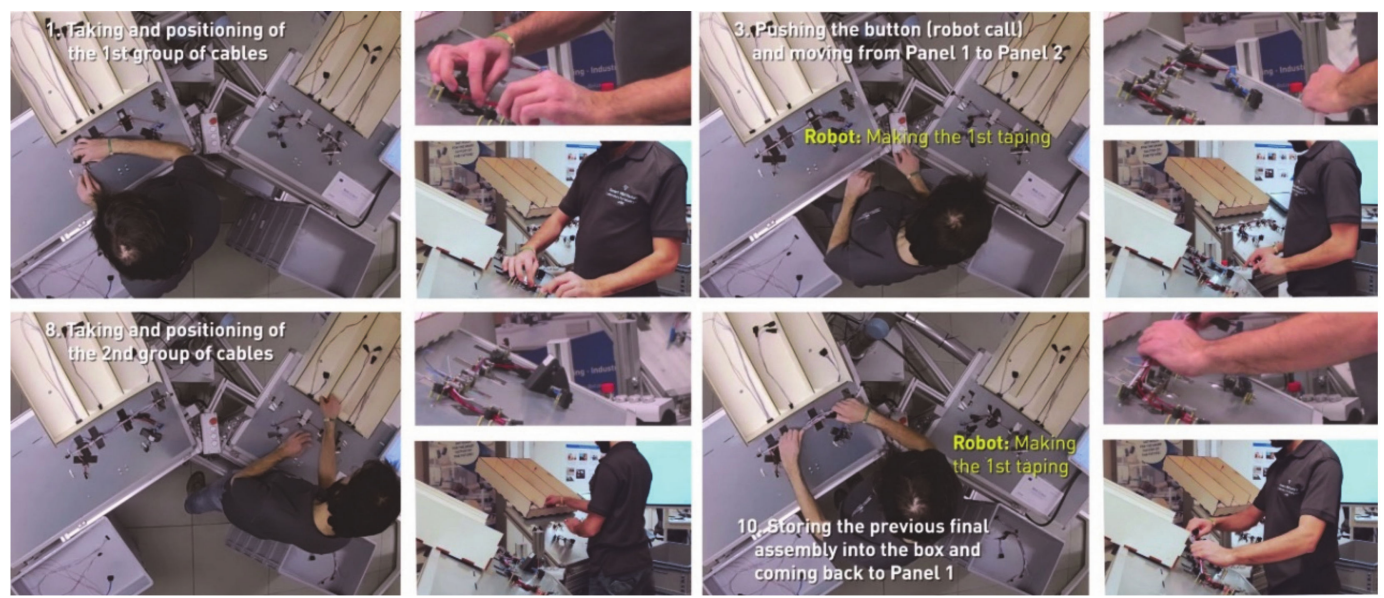

Figure 6. Pictures of experiments with the new assembly cycle.

\subsubsection{Manual Handling Improvements}

Table 9 summarizes the results of the OCRA check-list carried out on the new workstation. By comparing the final check list values in Table 9 with the ones of Table 5 (related to the manual workstation), it is evident that the operator's work conditions in terms of manual handlings are considerably improved in the new workstation. The overall values were reduced by $12.0 \%$ for the right part and by $28 \%$ for the left part. In particular, the final indexes changed from 15.8 to 13.9 for the right side and from 15.8 to 11.4 for the left side. This reduction will provide important benefits in terms of biomechanical overload related to manual handlings. In particular, the use of the collaborative robot considerably reduced the multipliers related to the dynamic and static constant of frequency, the posture, and the movements for different body regions. This is possible since the parallel work allows a reduction of the work rhythm. In addition, the use of the robot for the taping tasks reduces the operator's average awkward postures and movements. 
Table 9. Summary of the other multipliers and final estimation of the workstation risk (collaborative workstation). The percentage of indexes reduction between manual and collaborative workstation is highlighted in the brackets.

\begin{tabular}{|c|c|c|c|c|}
\hline \multicolumn{2}{|c|}{ Multiplier } & $\begin{array}{l}\text { Right Part } \\
\text { Value }\end{array}$ & $\begin{array}{l}\text { Left Part } \\
\text { Value }\end{array}$ & Motivation \\
\hline \multicolumn{2}{|c|}{ Recovery multiplier } & \multicolumn{2}{|c|}{1.33} & $\begin{array}{l}\text { It was supposed that the shift ( } 8 \mathrm{~h}) \text { is interspersed with a break } \\
\text { (1h). As a result, the number of hours without recovery period } \\
\text { is } 4 \text {, which means a multiplier equal to } 1.33\end{array}$ \\
\hline \multicolumn{2}{|c|}{$\begin{array}{l}\text { Constant of frequency } \\
\text { (dynamic actions) }\end{array}$} & $3(-25 \%)$ & $3(-25 \%)$ & $\begin{array}{l}\text { The movements of the arms are rapid ( } 40 \text { action/min). There } \\
\text { is the possibility of short interruptions. This means a } \\
\text { multiplier equal to } 3 .\end{array}$ \\
\hline \multicolumn{2}{|c|}{$\begin{array}{l}\text { Constant of frequency } \\
\text { (static actions) }\end{array}$} & $2.5(-44 \%)$ & $2.5(-44 \%)$ & $\begin{array}{l}\text { The operator handles the taping pistol and the cables for more } \\
\text { than half of the assembly cycle (there is a pinch for about the } \\
70 \% \text { of the time for both the right and the left hands). This } \\
\text { means a multiplier equal to } 2.5 \text {. }\end{array}$ \\
\hline \multicolumn{2}{|c|}{ Force multiplier } & 0 & 0 & $\begin{array}{l}\text { According to the operator interviews, the assembly tasks do } \\
\text { not require the use of force (Borg scale values lower than } 3 \text { ). }\end{array}$ \\
\hline \multirow{4}{*}{$\begin{array}{l}\text { Posture and } \\
\text { movements } \\
\text { multiplier }\end{array}$} & Shoulder & $1(-83 \%)$ & $0(-100 \%)$ & \multirow{4}{*}{$\begin{array}{l}\text { The movements and related postures were studied according } \\
\text { to guidelines provided in the check list. }\end{array}$} \\
\hline & Elbow & $8(+300 \%)$ & 6 & \\
\hline & Wrist & 0 & 0 & \\
\hline & Hand & $0(-25 \%)$ & $0(-25 \%)$ & \\
\hline \multicolumn{2}{|c|}{ Stereotype } & 0 & 0 & According to the definition, there is no stereotype \\
\hline \multicolumn{2}{|c|}{ Additional factors score } & 0 & 0 & According to the definition, there are no additional factors \\
\hline \multicolumn{2}{|c|}{ Multiplier for net duration } & \multicolumn{2}{|c|}{0.95} & $\begin{array}{l}\text { It was supposed that some working interruptions sometimes } \\
\text { occur. As a result, the total net duration of repetitive tasks is } \\
361-420 \mathrm{~min} / \mathrm{shift} \text {, which means a multiplier equal to } 0.95\end{array}$ \\
\hline \multicolumn{2}{|c|}{ Final Check-list values } & 13.9 & 11.4 & \multirow{3}{*}{ Yellow } \\
\hline \multicolumn{2}{|c|}{ Final risk estimation } & light & light & \\
\hline \multicolumn{2}{|c|}{ Reduction percentage } & $-12.0 \%$ & $-28 \%$ & \\
\hline
\end{tabular}

\subsubsection{Postural Improvements}

The postural assessment results are summarized in Table 10. The large part of the RULA values for different body regions were lower than the ones of the manual workstation. The operator's postures were considerably improved in the new workstation. The ergonomic benefits provided by changing the workstation from the manual to the collaborative one in terms of RULA values are shown in Table 11. The overall workstation values were reduced by $50 \%$ for the left part and by $57 \%$ for the right part (which are the combination of the left or right arm and related wrist analysis with the neck, trunk, and leg analysis). In particular, they changed from 6 to 3 for the left side and from 7 to 3 for the right side. This reduction will provide important benefits in terms of working postures. In particular, the use of the collaborative robot and the new layout reduced considerably the impact of the postures for different body regions.

\subsubsection{Production Efficiency Improvements}

The cycle time of the proposed solution is about $35 \mathrm{~s} / \mathrm{part}$, it was computed as an average value of the cycle times of the different experiments conducted with the prototype assembly station. In particular, such a value was obtained by dividing by two the overall assembly time which is needed for the parallel fabrication of two harnesses (one for each panel). The original cycle time was around $40 \mathrm{~s} /$ part for each workstation. Therefore, the new assembly cycle is more efficient than the original one: the cycle time is reduced by $12.3 \%$, which means about $1460 \mathrm{~h} /$ year in terms of "saved manual labor". 
Table 10. RULA results analysis of the new workstation.

\begin{tabular}{|c|c|c|c|}
\hline $\mathrm{Nr}$ & Task & $\begin{array}{l}\text { Final Value } \\
\text { Left Side }\end{array}$ & $\begin{array}{l}\text { Final Value } \\
\text { Right Side }\end{array}$ \\
\hline 1 & Picking the $1^{\text {st }}$ wire harness the box & 2 & 2 \\
\hline 2 & Positioning the $1^{\text {st }}$ wire harness into the frame & 3 & 3 \\
\hline 3 & Picking the $2^{\text {nd }}$ wire harness from the box & 2 & 2 \\
\hline 4 & Positioning the $2^{\text {nd }}$ wire harness into the frame & 2 & 2 \\
\hline 5 & Adjusting the first cable group on the second cable group & 2 & 2 \\
\hline 6 & Pushing the button (robot call) & 3 & 3 \\
\hline 7 & Moving from Panel 1 to Panel 2 & 2 & 2 \\
\hline 8 & Taking the previous final assembly from the frame & 3 & 3 \\
\hline 9 & Storing the previous final assembly into the box & 3 & 3 \\
\hline 10 & Moving from Panel 2 to Panel 1 & 2 & 2 \\
\hline 11 & Picking the $3^{\text {rd }}$ wire harness from the box & 2 & 3 \\
\hline 12 & Positioning the $3^{\text {rd }}$ wire harness into the frame & 3 & 3 \\
\hline 13 & Pushing the button (robot call) & 3 & 3 \\
\hline 14 & Moving from Panel 1 to Panel 2 & 2 & 2 \\
\hline \multicolumn{4}{|c|}{ Perform the same tasks (from 1 to 6 ) on Panel 2 and then come back to Panel $1^{* * *}$} \\
\hline 15 & Taking final assembly from the frame & 3 & 3 \\
\hline \multirow[t]{2}{*}{16} & Storing the final assembly into the box & 3 & 3 \\
\hline & Max values (Overall values) & 3 & 3 \\
\hline
\end{tabular}

*** Since the layout of Panel 2 is specular to Panel 1 and since the assembly sequence is the same, no other or different tasks are required for harness assembly on Panel 2. For this reason, from a postural point of view, an additional RULA analysis of the assembly tasks related to Panel 2 was not required (because the results will be comparable to the one calculated for Panel 1 tasks).

Table 11. RULA values for each analyzed body region.

\begin{tabular}{|c|c|c|c|c|c|c|c|}
\hline & & \multicolumn{6}{|c|}{ RULA Analysis Results (Max Values for Each Posture) } \\
\hline & & \multicolumn{2}{|c|}{ Actual Workstation } & \multicolumn{2}{|c|}{ Collaborative Workstation } & \multicolumn{2}{|c|}{ Index Variation } \\
\hline & & Left Side & Right Side & Left Side & Right Side & Left Side & Right Side \\
\hline \multirow{6}{*}{$\begin{array}{l}\text { Arm and } \\
\text { Wrist } \\
\text { Analysis }\end{array}$} & Upper Arm Posture Scores & 4 & 6 & 2 & 2 & -2 & -4 \\
\hline & Lower Arm Posture Scores & 3 & 3 & 2 & 2 & -1 & -1 \\
\hline & Wrist Posture Scores & 3 & 4 & 2 & 2 & -1 & -2 \\
\hline & Wrist Twist Posture Scores & 2 & 2 & 2 & 2 & 0 & 0 \\
\hline & Muscle Use Scores & 0 & 0 & 0 & 0 & 0 & 0 \\
\hline & Force/Load Scores & 0 & 0 & 0 & 0 & 0 & 0 \\
\hline \multirow{5}{*}{$\begin{array}{c}\text { Neck, } \\
\text { Trunk, } \\
\text { and Leg } \\
\text { Analysis }\end{array}$} & Neck Posture Scores & \multicolumn{2}{|c|}{4} & \multicolumn{2}{|c|}{3} & \multicolumn{2}{|c|}{-1} \\
\hline & Trunk Posture Scores & \multicolumn{2}{|c|}{4} & \multicolumn{2}{|c|}{2} & \multicolumn{2}{|c|}{-2} \\
\hline & Leg Posture Scores & \multicolumn{2}{|c|}{1} & \multicolumn{2}{|c|}{1} & \multicolumn{2}{|c|}{0} \\
\hline & Muscle Use Scores & \multicolumn{2}{|c|}{0} & \multicolumn{2}{|c|}{0} & \multicolumn{2}{|c|}{0} \\
\hline & Force/Load Scores & \multicolumn{2}{|c|}{0} & \multicolumn{2}{|c|}{0} & \multicolumn{2}{|c|}{0} \\
\hline \multicolumn{2}{|c|}{ Max values (overall values) } & 6 & 7 & 3 & 3 & -3 & -4 \\
\hline \multicolumn{6}{|c|}{ Improvements (reduction \% of overall workstation values) } & $50 \%$ & $57 \%$ \\
\hline
\end{tabular}

\section{Discussion and Conclusions}

In this work, a manual workstation for wire harness assembly was transformed into a collaborative one. According to the formal definition, the proposed result is a co-existence solution, since the robot is 
supporting the human without providing a real hand-by-hand physical interaction. This was possible by properly introducing a collaborative robot and by changing the working layout and the related assembly cycle. The main driver for the conversion was the improvement of operators' physical ergonomics. To this end, a framework was proposed to perform an accurate ergonomics assessment of the starting situation. Such a framework is based on ergonomics standards and state-of-the-art-methods for the ergonomic analyses. It is suitable for analyzing the manual assembly activities that are typically carried out in a workstation.

In order to preliminarily evaluate if the introduction in the manual assembly of a collaborative robot is beneficial, a methodology called Quick Assessment algorithm was exploited. It considered the benefits that the integration of a collaborative robot could provide to the manual process in terms of ergonomics and safety, product and process quality, and economics.

After that, the guidelines followed to design the new collaborative assembly workstation, starting from the existing one by particularly focusing on physical ergonomics and production efficiency, were outlined and applied.

Finally, the developed solution was implemented in the SMF laboratory through a TRL 4 prototype and its performance assessed. The achieved results show that the ergonomics indexes related to manual handlings (OCRA check-list) and postures (RULA values) were considerably reduced in the new workstation. In particular, the biomechanical overload of the worker was reduced by $12.0 \%$ for the right part and by $28 \%$ for the left part in terms of manual handling and by $50 \%$ for the left part and by $57 \%$ for the right part in terms of working postures. In addition, the estimated cycle time was reduced by $12.3 \%$. Considering the annual productivity, this improvement means a potential annual reduction of 1460 working hours.

The re-design approach introduced in this work is based on solutions that are effectively and simply utilizable by SMEs. The use of the framework for the identification of not-ergonomic tasks which could be improved by integrating a collaborative robot, the Quick Assessment algorithm as well as the virtual simulations are smart and easy-to-use tools for a proper design of a collaborative workstation starting from a manual one. The implementation of a prototype in a learning factory laboratory based on a real industrial case study provided by a manufacturing SME confirmed the effectiveness of the proposed solutions.

Although the results were satisfactory, both the employed methodologies and the developed collaborative workstation could be further improved, as discussed in the below.

1. Physical ergonomic assessment:

The framework presented for the physical ergonomics could be improved and generalized by using a different methodology for the assessment of the working postures, even if the RULA method is quick and easy to use; indeed, it is suggested to use such an approach only for preliminary postural assessment. A possible improvement relies on replacing the RULA method with the standardized guidelines included in ISO 11226 [31], as for the other methodologies mentioned in the framework.

2. Ergonomic improvements:

The achieved results are more than satisfactory in terms of reduction of work-related biomechanical overload. Even if the project goal was successfully achieved, the final OCRA check-list and RULA values were slightly over the optimal zone, i.e., the green one. Better results could be achieved by integrating the proposed technical solutions (which usually have the major impact) with organizational solutions. This should provide further benefits and a real possibility to achieve the green zone.

3. Cycle time:

Even though the achieved results were satisfactory, the cycle time could be shortened by optimizing the robot trajectories and/or developing a new taping pistol (specially designed for robotic applications). 
In both the cases, the time taken by the robot for performing the assembly cycle would be reduced and the cycle time improved. Indeed, the bottleneck (in terms of cycle time) of the new collaborative workstation is the second set of tapings (from the second to the seventh). A minimum speeding up of such tasks can bring enormous benefits to the annual productivity: a reduction of about the $5 \%$ of the robot cycle time $(\approx 1 \mathrm{~s}$ less than the current overall cycle time) results in a potential reduction of 292 annual working hours.

In addition to the economic considerations, a taping pistol which is specially designed for robotic applications could provide several benefits also in terms of product quality.

4. Future research directions:

Future research should focus on the possibility to autonomously and dynamically adapt the workstation elements according to operators' psychophysical work conditions, needs, and wants [32]. This will surely improve both physical and cognitive ergonomics and therefore have a good impact on productivity. These improvements would be possible by properly integrating the robot systems with specific monitoring sensors and wearable devices. In addition, the possibility to increase the system flexibility by rapidly adapting the assembly to different product variants should be investigated.

Author Contributions: Conceptualization, all the authors.; Methodology, L.G.; Software, F.A.M.; Validation, L.G., I.P.; Formal Analysis, L.G.; Writing-Original Draft Preparation, L.G.; Writing-Review and Editing, I.P., E.R. and R.V.; Supervision, E.R. and R.V.; Project Administration, I.P. All authors have read and agreed to the published version of the manuscript.

Acknowledgments: The research leading to these results can be framed within the Wire Cobots project, a cascade funding project which receives funding from the European Commission for organizing the Robotics Application Oriented Research Experiment, under the ESMERA Funding Agreement (agreement No 780265). Further this research and the development of the Quick Assessment methodology belongs to the project "SME 4.0-Industry 4.0 for SMEs" and has received funding from the European Union's Horizon 2020 R\&I programme under the Marie Skłodowska-Curie grant agreement No 734713.

Conflicts of Interest: The authors declare no conflict of interest.

\section{Appendix A}

\section{Appendix A.1. NIOSH Lifting Equation}

A large proportion of occupational back disorders originate from improper manual lifting activities that provide operators' biomechanical and psychological overload as well as psychosocial factors. For these reasons, NIOSH proposed a practical evaluation procedure for the analysis of the physical demands of two-handed manual lifting [18]. The methodology is composed of the assessment of two main factors: the recommended weight limit and the lifting index. The former is calculated through the analysis of main task features, such as the geometry of the hand location, frequency of lifting, work duration, and type of hand coupling required for the task. The latter estimates the physical demand related to the task and is defined as the ratio between the actual weight of the load lifted and the recommended weight limit for the same activity [20].

\section{Appendix A.2. OCRA Check List}

Manual handling activities could be potentially harmful for operators if proper physical ergonomics expedients are not correctly implemented. In general, it is advisable to avoid or reduce as much as possible these operations through work enlargements, job rotation, and/or automation. Especially in the case of repetitive tasks characterized by manual handling of low loads at high frequency, industrial robotics could be an efficient solution [22]. The OCRA check list is a quantitative methodology for the evaluation of the biomechanical overload related to upper limbs in the case of manual handling of low loads at high frequency. This method is a simplified form of the so called "OCRA index" and is part of the ISO standard 12228-3 [22] about manual handling ergonomics and considers the following risk factors (for the right and left parts): frequency of technical actions, repetitiveness, awkward postures 
(for shoulders, elbows, wrists, and hands), force, additional factors, lack of recovery periods, duration of repetitive task. The method is based on the combination of the following multipliers [22]:

-Recovery multiplier: it evaluates the recovery time, which is defined as any time in which the upper limb is primarily physically inactive;

- Constant of frequency: it evaluates the contribution of the movement frequency to the development of a muscle-tendon disorder. The technical action may be dynamic (characterized by movement) or static (characterized by holding a single posture, such as when a worker must hold an object in their hand);

-Force multiplier: it evaluates the operator's use of force during the manual tasks by means of interviewing them and asking to describe the subjectively perceived muscular effort made when they are carrying out a repetitive task;

-Posture and movements multiplier: it evaluates the contribution of awkward postures and movements of shoulder, elbow, wrist, and hand (type of grip and finger movements) required during the activity to the work-related muscle-tendon disorders;

-Additional factors score: it evaluates the further contribution of additional physico-mechanical factors and/or additional socio-organizational factors. These additional factors may increase the risk if they are present and, as a consequence, should be carefully considered;

-Multiplier for net duration: it aims to adapt the risk value by weighing the final index for the real duration of the repetitive work.

As output, it provides the intrinsic risk of a certain work situation or workplace by providing an exposure level classified through a three-zone system. These zones are represented by different colors, as following:

-Green zone (check-list value $\leq 7.5$ ): if the results of the analysis of a certain activity are within this zone, the overall risk is considered to be acceptable;

-Yellow zone $(7.5<$ check-list value $\leq 11.0)$ : if the results of the analysis of a certain activity are within this zone, a more detailed risk assessment is needed or else remedial action should be taken to reduce the risk to the green zone;

-Red zone $(11<$ check-list value $\leq 14.0$ for light red, $14.0<$ check-list value $\leq 22.5$ for medium red, and check-list value $>22.5$ for high red): if the results of the analysis of a certain activity are within this zone, then the work is judged to be harmful for the operators.

\section{Appendix A.3. RULA Method}

RULA is a guided survey method for simple and fast evaluation of the musculoskeletal system through the analysis of postures. It involves the analysis of the neck, trunk, and upper limbs, along with muscle function and the external loads experienced by the body. Basically, the method allows the study of the upper body activities by using body part diagrams integrated with code for joint angles, body postures, load/force, coupling, and muscle activity [23]. The evaluation is done on a single worksheet page composed by different sequential tables to fulfill. Scores are then entered based on both the two central regions: section " $\mathrm{A}$ " for wrist and arm and section " $\mathrm{B}$ " for trunk and neck (and eventually legs). By combining the results of these two first sections, it is possible to calculate a final score (section "C") which is related to a proposed a scale of action levels:

-Green zone (RULA value between 1 and 2): if the results of the analysis of a certain activity are within this zone, then the work is acceptable and no improvement action are required;

-Pale yellow zone (RULA value between 3 and 4): if the results of the analysis of a certain activity are within this zone, further investigations are necessary and changes may be required;

-Dark yellow zone (RULA value between 5 and 7): if the results of the analysis of a certain activity are within this zone, further investigations are necessary and changes are required soon;

- Red zone (RULA value equal or higher than 7): if the results of the analysis of a certain activity are within this zone, further investigations are necessary and changes are required immediately. 
These action levels should provide a guide to the level of risk and need for action to conduct more detailed assessments. Basically, they evaluate whether the posture is acceptable or requires further investigation and change, which means the possibility to introduce the collaborative robot for physical ergonomics improvement.

Even if the method was originally proposed for the investigations of work-related upper limb disorders, the results are usually not sufficient for a comprehensive evaluation of the biomechanical overload related to the assembly activities. Due to the fact that RULA is easy to use by enabling a quick study without requiring a higher degree in ergonomics or even the need for expensive equipment, this method is often chosen for the postural analysis.

\section{Appendix A.4. RULA Evaluation of the Current Assembly Process}

Tables A1 and A2 explain in details the RULA evaluation for each body district involved in the manual assembly (Table 3). The summary of the final results is provided in Table 6.

Table A1. Summary of the RULA analysis related to the arm and wrist values.

\begin{tabular}{|c|c|c|c|c|c|c|c|c|c|c|c|c|}
\hline \multirow[b]{3}{*}{ Task nr. } & \multicolumn{12}{|c|}{ A-Arm and Wrist Analysis } \\
\hline & \multicolumn{2}{|c|}{$\begin{array}{l}\text { Upper Arm } \\
\text { Posture } \\
\text { Scores }\end{array}$} & \multicolumn{2}{|c|}{$\begin{array}{l}\text { Lower Arm } \\
\text { Posture } \\
\text { Scores }\end{array}$} & \multicolumn{2}{|c|}{$\begin{array}{l}\text { Wrist Posture } \\
\text { Scores }\end{array}$} & \multicolumn{2}{|c|}{$\begin{array}{l}\text { Wrist Twist } \\
\text { Posture } \\
\text { Scores }\end{array}$} & \multicolumn{2}{|c|}{$\begin{array}{c}\text { Look-Up } \\
\text { Posture Index } \\
\text { in Table A }\end{array}$} & \multicolumn{2}{|c|}{$\begin{array}{c}\text { Find row in } \\
\text { Table C }\end{array}$} \\
\hline & Left & Right & Left & Right & Left & Right & Left & Right & Left & Right & Left & Right \\
\hline 1 & 4 & 3 & 3 & 1 & 2 & 3 & 2 & 2 & 5 & 4 & 5 & 4 \\
\hline 2 & 1 & 1 & 2 & 2 & 3 & 2 & 2 & 2 & 3 & 2 & 3 & 2 \\
\hline 3 & 1 & 2 & 2 & 3 & 1 & 3 & 2 & 2 & 3 & 4 & 3 & 4 \\
\hline 4 & 3 & 3 & 2 & 2 & 3 & 4 & 2 & 2 & 4 & 5 & 4 & 5 \\
\hline 5 & 3 & 4 & 1 & 2 & 3 & 3 & 2 & 2 & 4 & 5 & 4 & 5 \\
\hline 6 & 2 & 2 & 2 & 1 & 2 & 2 & 2 & 1 & 3 & 3 & 3 & 3 \\
\hline 7 & 3 & 6 & 1 & 1 & 3 & 4 & 2 & 1 & 4 & 8 & 4 & 8 \\
\hline 8 & 2 & 2 & 2 & 1 & 3 & 2 & 2 & 1 & 4 & 3 & 4 & 3 \\
\hline 9 & 4 & 4 & 1 & 2 & 3 & 3 & 2 & 2 & 5 & 5 & 5 & 5 \\
\hline 10 & 3 & 3 & 2 & 2 & 3 & 4 & 2 & 2 & 4 & 5 & 4 & 5 \\
\hline 11 & 2 & 2 & 2 & 1 & 2 & 2 & 2 & 1 & 3 & 3 & 3 & 3 \\
\hline 12 & 3 & 5 & 2 & 2 & 3 & 3 & 2 & 1 & 4 & 6 & 4 & 6 \\
\hline 13 & 3 & 6 & 1 & 1 & 3 & 3 & 2 & 1 & 4 & 7 & 4 & 7 \\
\hline 14 & 2 & 6 & 1 & 2 & 3 & 4 & 2 & 1 & 4 & 9 & 4 & 9 \\
\hline 15 & 2 & 6 & 1 & 2 & 3 & 4 & 2 & 1 & 4 & 9 & 4 & 9 \\
\hline 16 & 2 & 6 & 1 & 2 & 3 & 3 & 2 & 2 & 4 & 9 & 4 & 9 \\
\hline 17 & 1 & 6 & 2 & 1 & 3 & 4 & 2 & 2 & 3 & 9 & 3 & 9 \\
\hline 18 & 2 & 2 & 1 & 1 & 2 & 2 & 2 & 1 & 3 & 3 & 3 & 3 \\
\hline 19 & 3 & 3 & 2 & 3 & 3 & 4 & 2 & 2 & 4 & 5 & 4 & 5 \\
\hline
\end{tabular}


Table A2. Summary of the RULA analysis related to the neck, trunk, and leg values.

\begin{tabular}{|c|c|c|c|c|c|}
\hline \multirow[b]{2}{*}{ Task nr. } & \multicolumn{5}{|c|}{ B-Neck, Trunk, and Leg Analysis } \\
\hline & $\begin{array}{l}\text { Neck Posture } \\
\text { Scores }\end{array}$ & $\begin{array}{l}\text { Trunk Posture } \\
\text { Scores }\end{array}$ & $\begin{array}{l}\text { Leg Posture } \\
\text { Scores }\end{array}$ & $\begin{array}{l}\text { Lookup Posture } \\
\text { Index in Table B }\end{array}$ & $\begin{array}{l}\text { Find Column } \\
\text { in Table C }\end{array}$ \\
\hline 1 & 3 & 3 & 1 & 4 & 4 \\
\hline 2 & 3 & 1 & 1 & 3 & 3 \\
\hline 3 & 4 & 3 & 1 & 6 & 6 \\
\hline 4 & 4 & 3 & 1 & 6 & 6 \\
\hline 5 & 4 & 3 & 1 & 6 & 6 \\
\hline 6 & 4 & 3 & 1 & 6 & 6 \\
\hline 7 & 4 & 4 & 1 & 7 & 7 \\
\hline 8 & 4 & 3 & 1 & 6 & 6 \\
\hline 9 & 3 & 2 & 1 & 3 & 3 \\
\hline 10 & 4 & 3 & 1 & 6 & 6 \\
\hline 11 & 4 & 3 & 1 & 6 & 6 \\
\hline 12 & 4 & 3 & 1 & 6 & 6 \\
\hline 13 & 4 & 4 & 1 & 7 & 7 \\
\hline 14 & 4 & 4 & 1 & 7 & 7 \\
\hline 15 & 4 & 4 & 1 & 7 & 7 \\
\hline 16 & 4 & 4 & 1 & 7 & 7 \\
\hline 17 & 4 & 3 & 1 & 6 & 6 \\
\hline 18 & 3 & 2 & 1 & 3 & 3 \\
\hline 19 & 4 & 3 & 1 & 6 & 6 \\
\hline
\end{tabular}

\section{References}

1. Pedersen, M.R.; Nalpantidis, L.; Andersen, R.S.; Schou, C.; Bøgh, S.; Krüger, V.; Madsen, O. Robot skills for manufacturing: From concept to industrial deployment. Robot. Comput. Integr. Manuf. 2016, 37, $282-291$. [CrossRef]

2. Kagermann, H.; Helbig, J.; Hellinger, A.; Wahlster, W. Recommendations for Implementing the Strategic Initiative INDUSTRIE 4.0: Securing the Future of German Manufacturing Industry; Final Report of the Industrie 4.0 Working Group; Forschungsunion: Acatech, Munich, 2013.

3. Braccini, A.M.; Margherita, E.G. Exploring organizational sustainability of industry 4.0 under the triple bottom line: The case of a manufacturing company. Sustainability 2018, 11, 36. [CrossRef]

4. International Ergonomics Association. 2019. Definition and Domains of Ergonomics. Available online: https://iea.cc/what-is-ergonomics/ (accessed on 12 December 2019).

5. Zhong, R.Y.; Xu, X.; Klotz, E.; Newman, S.T. Intelligent manufacturing in the context of industry 4.0: A review. Engineering 2017, 3, 616-630. [CrossRef]

6. Gualtieri, L.; Palomba, I.; Wehrle, E.; Vidoni, R. The Opportunities and Challenges of SME Manufacturing Automation: Safety and Ergonomics in Human-Robot Collaboration. In InDustry 4.0 for SMEs Challenges, Opportunities and Requirements; Matt, D.T., Modrak, V., Zsifkovits, H., Eds.; Palgrave Macmillan: Basingstoke, UK, 2019.

7. Castro, P.R.; Högberg, D.; Ramsen, H.; Bjursten, J.; Hanson, L. Virtual simulation of human-robot collaboration workstations. In Congress of the International Ergonomics Association; Springer: Cham, Switzerland, 2018; pp. 250-261. 
8. Lietaert, P.; Billen, N.; Burggraeve, S. Model-based Multi-Attribute Collaborative Production Cell Layout Optimization. In Proceedings of the 2019 20th International Conference on Research and Education in Mechatronics (REM), Wels, Austria, 23-24 May 2019; pp. 1-7.

9. Mateus, J.C.; Claeys, D.; Limère, V.; Cottyn, J.; Aghezzaf, E.H. A structured methodology for the design of a human-robot collaborative assembly workplace. Int. J. Adv. Manuf. Technol. 2019, 102, 2663-2681. [CrossRef]

10. Petruck, H.; Faber, M.; Giese, H.; Geibel, M.; Mostert, S.; Usai, M.; Mertens, A.; Brandl, C. Human-robot collaboration in manual assembly-A collaborative workplace. In Congress of the International Ergonomics Association; Springer: Cham, Switzerland, 2018; pp. 21-28.

11. Dombrowski, U.; Stefanak, T.; Perret, J. Interactive simulation of human-robot collaboration using a force feedback device. Procedia Manuf. 2017, 11, 124-131. [CrossRef]

12. El Makrini, I.; Merckaert, K.; Lefeber, D.; Vanderborght, B. Design of a collaborative architecture for human-robot assembly tasks. In Proceedings of the 2017 IEEE/RSJ International Conference on Intelligent Robots and Systems (IROS), Vancouver, BC, Canada, 24-28 September 2017; pp. 1624-1629.

13. Schmidtler, J.; Knott, V.; Hölzel, C.; Bengler, K. Human Centered Assistance Applications for the working environment of the future. Occup. Ergon. 2015, 12, 83-95. [CrossRef]

14. Heydaryan, S.; Suaza Bedolla, J.; Belingardi, G. Safety design and development of a human-robot collaboration assembly process in the automotive industry. Appl. Sci. 2018, 8, 344. [CrossRef]

15. Gualtieri, L.; Rauch, E.; Vidoni, R.; Matt, D.T. An Evaluation Methodology for the Conversion of Manual Assembly Systems into Human-Robot Collaborative Workcells. In Proceedings of the 2019 International Conference in Flexible Automation and Intelligent Manufacturing (FAIM 2019), Limerick, Ireland, 24-28 June 2019.

16. International Organization for Standardization. ISO-TR 12295-Ergonomics-Application Document for ISO Standards on Manual Handling (ISO 11228-1, ISO 11228-2 and ISO 11228-3) and Evaluation of Static Working Postures (ISO 11226) (ISO-TR12295: 2014). 2014. Available online: https://www.iso.org/standard/51309.html (accessed on 12 December 2019).

17. International Organization for Standardization. ISO 11228-2—Ergonomics-Manual Handling-Part 2: Pushing and Pulling (ISO 11228-2:2007). 2007. Available online: https://www.iso.org/standard/26521.html (accessed on December 2019).

18. Waters, T.R.; Putz-Anderson, V.; Garg, A.; Fine, L.J. Revised NIOSH equation for the design and evaluation of manual lifting tasks. Ergonomics 1993, 36, 749-776. [CrossRef] [PubMed]

19. International Organization for Standardization. ISO 11228-1-Ergonomics-Manual handling-Part 1: Lifting and Carrying (ISO 11228-1:2003). 2003. Available online: https://www.iso.org/standard/26520.html (accessed on December 2019).

20. Waters, T.R.; Lu, M.L.; Piacitelli, L.A.; Werren, D.; Deddens, J.A. Efficacy of the revised NIOSH lifting equation to predict risk of low back pain due to manual lifting: Expanded cross-sectional analysis. J. Occup. Environ. Med. 2011, 53, 1061-1067. [CrossRef] [PubMed]

21. Colombini, D. Risk Assessment and Management of Repetitive Movements and Exertions of Upper Limbs: Job Analysis, Ocra Risk Indicies, Prevention Strategies and Design Principles (Vol. 2); Elsevier: Amsterdam, The Netherlands, 2002.

22. International Organization for Standardization. (2007). ISO 11228-3-Ergonomics-Manual Handling-Part 3: Handling of Low Loads at High Frequency. International Organization for Standardization. (ISO 11228-3:2007). 2007. Available online: https://www.iso.org/standard/26522.html (accessed on 13 December 2019).

23. McAtamney, L.; Corlett, E.N. RULA: A survey method for the investigation of work-related upper limb disorders. Appl. Ergon. 1993, 24, 91-99. [CrossRef]

24. International Organization for Standardization. (2002). ISO 14738:2002—Safety of Machinery-Anthropometric Requirements for the Design of Workstations at Machinery. International Organization for Standardizatio. (ISO 14738:2002). 2002. Available online: https://www.iso.org/standard/27556.html (accessed on 8 December 2019).

25. The Company. 2019. Available online: https://elvez.si/en/ (accessed on 12 December 2019).

26. ESMERA Open Calls. 2020. Available online: http://www.esmera-project.eu/open-calls/ (accessed on 3 April 2020).

27. Gualtieri, L.; Rojas, R.; Carabin, G.; Palomba, I.; Rauch, E.; Vidoni, R.; Matt, D.T. Advanced automation for SMEs in the I4. 0 revolution: Engineering education and employees training in the smart mini factory laboratory. In Proceedings of the 2018 IEEE International Conference on Industrial Engineering and Engineering Management (IEEM), Bangkok, Thailand, 16-19 December 2018; pp. 1111-1115. 
28. Carretta Automations. 2019. Available online: http://www.carrettaautomazioni.it/en/ (accessed on 20 December 2019).

29. ESMERA Elvez Challenge. 2020. Available online: https://www.youtube.com/watch?v=DA1nueKqQt8 (accessed on 8 January 2020).

30. Tecnomatix. 2020. Available online: https://www.plm.automation.siemens.com/global/en/products/tecnomatix/ (accessed on 8 January 2020).

31. International Organization for Standardization. ISO 11226: 2000/COR 1:2006. Ergonomics-Evaluation of Static Working Postures-Technical Corrigendum 1. International Organization for Standardizatio. (ISO 11226: 2000/COR 1:2006). 2006. Available online: https://www.iso.org/standard/44143.html (accessed on 12 December 2019).

32. Gualtieri, L.; Rojas, R.A.; Ruiz Garcia, M.A.; Rauch, E.; Vidoni, R. Implementation of a Laboratory Case Study for Intuitive Collaboration between Man and Machine in SME Assembly. In Industry 4.0 for SMEs Challenges, Opportunities and Requirements; Matt, D.T., Modrak, V., Zsifkovits, H., Eds.; Palgrave Macmillan: Basingstoke, UK, 2019.

(C) 2020 by the authors. Licensee MDPI, Basel, Switzerland. This article is an open access article distributed under the terms and conditions of the Creative Commons Attribution (CC BY) license (http://creativecommons.org/licenses/by/4.0/). 